\title{
BMJ Open Mentors' perspectives on strengths and weaknesses of a novel clinical mentorship programme in Rwanda: a qualitative study
}

\author{
Sandrine Uwisanze, ${ }^{1}$ Anaclet Ngabonzima (i) ,2 Oliva Bazirete, ${ }^{3}$ \\ Celestin Hategeka, ${ }^{4}$ Cynthia Kenyon, ${ }^{5}$ Domina Asingizwe, ${ }^{6}$ Clementine Kanazayire, ${ }^{6}$ \\ David Cechetto ${ }^{7}$
}

To cite: Uwisanze $\mathrm{S}$, Ngabonzima A, Bazirete 0, et al. Mentors' perspectives on strengths and weaknesses of a novel clinical mentorship programme in Rwanda: a qualitative study. BMJ Open 2021;11:e042523. doi:10.1136/ bmjopen-2020-042523

- Prepublication history and additional materials for this paper are available online. To view these files, please visit the journal online (http://dx.doi. org/10.1136/bmjopen-2020042523).

Received 09 July 2020 Revised 09 February 2021 Accepted 19 February 2021

Check for updates

(c) Author(s) (or their employer(s)) 2021. Re-use permitted under CC BY-NC. No commercial re-use. See rights and permissions. Published by BMJ.

For numbered affiliations see end of article.

Correspondence to Sandrine Uwisanze; angesandra18@gmail.com

\section{ABSTRACT}

Objectives To identify mentors' perspectives on strengths and weaknesses of the Training, Support and Access Model for Maternal, Newborn and Child Health (TSAM$\mathrm{MNCH}$ ) clinical mentorship programme in Rwandan district hospitals. Understanding the perspectives of mentors involved in this programme can aid in the improvement of its implementation.

Design The study used a qualitative approach with indepth interviews.

Setting Mentors of TSAM-MNCH clinical mentorship programme mentoring health professionals at district hospitals of Rwanda.

Participants 14 TSAM mentors who had at least completed six mentorship visits on a regular basis in three selected district hospitals.

Results Mentors' accounts demonstrated an appreciation of the two mentoring structures which are interprofessional collaboration and training. These structures are highlighted as the strengths of the mentoring programme and they play a significant role in the successful implementation of the mentorship model. Inconsistency of mentoring activities and lack of resources emerged as major weaknesses of the clinical mentorship programme which could hinder the effectiveness of the mentoring scheme.

Conclusion The findings of this study highlight the strengths and weaknesses perceived by mentors of the TSAM-MNCH clinical mentorship programme, providing insights that can be used to improve its implementation. The study represents unique TSAM-MNCH structural settings, but its findings shed light on Rwandan health system issues that need to be further addressed to ensure better quality of care for mothers, newborns and children.

\section{INTRODUCTION}

High rates of maternal mortality remain a major concern for low/middle-income countries (LMICs) that face different challenges in providing quality care. According to the WHO, approximately 830 women die every day from preventable causes related to pregnancy and childbirth, 5.1 million babies are
Strengths and limitations of this study

- This was the first study to focus on a unique mentorship model at the district hospital level.

- Mentors are affiliated with the Training, Support and Access Model for Maternal, Newborn and Child Health (TSAM-MNCH) programme and this relationship can create bias and may have affected the data reported.

- The inclusion of other healthcare providers beyond the TSAM-MNCH catchment area would generate different perspectives about the programme.

stillborn or die every year in their first month of life, and $99 \%$ of all maternal and child deaths occur in LMICs. ${ }^{1-3}$ In addition, the WHO estimates that only $74 \%$ of live births globally benefited from skilled care during delivery, ${ }^{4}$ highlighting a need for increasing skilled healthcare workers in these settings. Rwanda has made considerable progress in reducing maternal and under-5 mortality. The maternal mortality ratio fell from 1160 deaths per 100000 live births in 2000 to 248 deaths in 2017, and under-5 mortality fell from 152 deaths per 1000 live births in 2005 to 50 deaths in $2015 .{ }^{56}$ Although Rwanda has made substantial improvements in maternal and child health, current maternal and child mortality rates are still high. In an effort to contribute to reducing child and maternal mortality, clinical mentorship programmes proven to improve the capacity of healthcare providers have been introduced in district hospitals and health facilities.

Onsite clinical mentorship is a form of ongoing practical training and consultation that takes place in a health facility where health workers treat patients and manage their cases to foster professional development and sustainable high quality of care. ${ }^{7-9}$ 
A clinical mentor is usually a practitioner with relevant experience, knowledge and skills that are transferable for the professional development of other less experienced healthcare workers. ${ }^{10}$ Evidence suggests that post-training supportive supervision and mentorship are effective in strengthening learning processes, and improving provider motivation and clinical performance. ${ }^{11-13}$ Studies conducted in Rwanda suggested that some of the reasons for low performance among healthcare providers can be traced through limited supervision and mentorship as well as insufficient support systems consistent with challenges reported in other similar settings. ${ }^{81415}$ Increasing the number of healthcare providers and training them to deliver quality care is a core component of health systems strengthening needed to achieve universal health coverage. ${ }^{10}$ The government of Rwanda encourages healthcare providers to participate in continuous professional development (CPD) programmes to enhance their skills and to further this goal; thus, the country has implemented a mentoring scheme. ${ }^{15}$ Some barriers that limit the implementation of mentorship programmes in Rwanda are found to be staff turnover and lack of materials and equipment. ${ }^{16}$

The Training, Support and Access Model for Maternal, Newborn and Child Health (TSAM-MNCH) in Rwanda is a partnership project with the primary mission of improving $\mathrm{MNCH}$ by working with local partners to improve health service access and delivery. ${ }^{17}$ Through its CPD stream, TSAM-MNCH designed and implemented a mentorship programme to increase health practitioners' ability to provide quality care and to bridge the gap between traditional theoretical training and practical training. ${ }^{17}$ This mentorship model was adopted from the Reproductive, Maternal, Newborn and Child Health Clinical Mentorship guidelines designed by the Rwandan Ministry of Health to improve the quality of MNCH. ${ }^{18}$ The TSAM-MNCH mentorship model is unique due to its extensive focus on interprofessional collaboration with the idea that $\mathrm{MNCH}$ services are inter-related. The mentorship model was developed and implemented in 6 out of 30 districts of Rwanda, namely Rulindo, Gicumbi, Gakenke, Muhanga, Gisagara and Ruhango. These six districts were assigned to the TSAM-MNCH project by the Rwandan Ministry of Health.

Since the launch of the mentorship programme, TSAM-MNCH has not evaluated the perspectives of mentors undertaking the mentorship activities at the assigned district hospitals. Their perspectives are essential to improve the implementation of the programme, therefore, this study contributed to that cause and it also aimed at adding to the existing literature on clinical mentoring in Rwanda. The objective of this study was to assess the perspectives of TSAM-MNCH mentors on the strengths and weaknesses of the mentorship model. The study will also assess the mentorship environment and highlight gaps and areas of improvement of the mentorship model.
METHODS

\section{Study setting}

The health system in Rwanda is dominated by publicly funded healthcare facilities that include health centres, dispensaries, district hospitals, national referral hospitals and university teaching hospitals. ${ }^{16}$ Compared with the health centres, district hospitals offer services with a higher level of complexity and expertise including surgeries and complex inpatient care such as the management of high-risk cases of mothers and children that have been referred from health centres. ${ }^{19}$ Rwanda has 42 district hospitals that serve as first-line referral hospitals and receive referrals from peripheral health facilities. ${ }^{20}$ District hospitals are generally staffed by nurses, midwives and generalist physicians with basic medical training. ${ }^{16}$ Despite the limited number of specialists and resources, district hospitals are fundamental to primary care, especially in remote areas. ${ }^{16}$ The mentorship activities were conducted in neonatal, maternity and paediatric wards in the district hospitals.

\section{Description of TSAM-MNCH clinical mentorship programme}

Through consultations with different key actors, the mentoring model was developed in early 2017 . The potential mentors to be part of this mentorship model were identified and selected among experienced healthcare providers permanently working in university (tertiary) referral hospitals. Consequently, mentors had to travel to take part in mentorship activities at the district hospitals where their mentees are based. Mentors were selected by TSAM-MNCH from different professional associations in their areas of competency. The selection was based on mentors' medical expertise, competency and willingness to transfer skills.

The programme was built on interprofessional collaboration which required mentors to work in a team. Each mentoring team had five health professionals consisting of a gynaecologist/obstetrician, a paediatrician, an anaesthetist, a midwife and a paediatric nurse. This was the first mentorship model to include anaesthesia providers recognising their crucial role in the reduction of maternal, newborn and child morbidity and mortality. Each mentor was assigned two to three mentees and each mentorship visit lasted 3 consecutive days, once in 2 months. Five hospitals in the Northern Province benefited from 15 mentorship visits, while the five hospitals in the Southern Province had 13 visits each.

The selected mentors received refresher courses in specific skills in their specialty and a training course on mentoring. This course on mentoring included crosscutting themes focusing on interprofessional collaboration, gender and ethics. In addition, mentors benefited from additional training including simulation and debriefing and quality improvement.

The district hospital management team was involved in the development and implementation of the mentorship model to ensure ownership of the model. This was done through the organisation of the preparatory 
meetings with hospitals before launching the mentoring programme. Coordination meetings with beneficiaries and implementers identified strategies to overcome the challenges encountered throughout the implementation of the mentoring. Challenges and strategies to overcome them were developed during these meetings.

Before starting mentorship activities, mentees filled out self-assessment surveys to identify areas that needed improvement. These surveys facilitated the mentor's efforts to teach effectively according to mentees' personal needs. The mentorship activities were based on the needs of each mentee and the gaps in each hospital service. Mentors also provided an assessment to give feedback to their mentees after each mentorship visit. The mentorship model encouraged a supportive mentorship environment for the mentor-mentee relationship and allowed constructive feedback and follow-up. In addition, the mentees' performance was determined using evaluation tools. This mentorship model allows healthcare professionals to collaborate and to cross-consult to ensure the delivery of quality care.

The teaching methodologies used by TSAM-MNCH mentors included bedside teaching and case scenario discussions, as well as simulation, case presentation, ward rounds, mortality and morbidity audit, debriefing sessions and managing clinical emergencies alongside the mentees. ${ }^{16}$ Each mentor works alongside their mentee to assist with daily medical assignments and assess the performance. The whole team of mentors and mentees can occasionally collaborate depending on the medical cases. This professional collaboration is most likely to happen because the mentorship programme focuses on areas that are inter-related. After each mentorship field visit, mentors fill out reflection forms.

\section{Study design and population}

This study was a descriptive design using a qualitative approach to assess the perspectives of TSAM$\mathrm{MNCH}$ mentors on the strengths and weaknesses of the mentorship model. The study participants included 50 active mentors mentoring health professionals in 10 district hospitals of TSAM-MNCH clinical mentorship programme catchment area. The researcher obtained a list of TSAM-MNCH mentors with their contact information from TSAM-MNCH administration, and then selected active mentors who had completed at least six mentorship field visits on a regular basis in TSAM$\mathrm{MNCH}$ assigned district hospitals. This was to ensure that mentors have sufficient knowledge and are familiar with the mentorship programme.

\section{Study sample and sampling procedure}

Initially, 18 mentors were purposively selected to participate in the study. Some participants were invited over the phone while others were invited face to face by the researcher. All the invitations were in Kinyarwanda language. With different reasons, four mentors were not able to participate, thus the study sample was 14 mentors who were representative of each profession. The sample consisted of three gynaecologists/obstetricians, three paediatricians, two anaesthetists, three midwives and three paediatric nurses. These four were not replaced because we observed that saturation was reached. Saturation was reached around the ninth interview and the researcher kept collecting data to make sure that each profession is represented in the study sample since the mentorship model is built on interprofessional collaboration and every profession plays a key and unique role in the programme.

\section{Data collection}

The methodology followed a Consolidated criteria for Reporting Qualitative research checklist (research checklist). Qualitative primary data were collected directly from participants using one-to-one in-depth interview. The interview guide (online supplemental file 1) was made up of 15 questions that led to an hour interview between the researcher and each participant. A semistructured interview guide was developed based on the research questions by the research team. Most questions were open ended and were based on mentorship activities and the perspectives of the mentors about the TSAMMNCH mentorship model: its strengths, weaknesses, gaps as well as areas of improvements. The interviews were electronically recorded and field notes were taken by the researcher.

All interviews took place in the hospital offices where mentors were conducting their mentorship visits and did not interfere with mentorship activities. Two interviews were done in the local language (Kinyarwanda) due to the participants' request and level of comfort. A Kinyarwanda interview guide that had been prepared was used for the two interviews. In general, the interviews lasted about an hour except for two interviews which lasted approximately $35 \mathrm{~min}$ because the participants had to abruptly leave to assist with an emergency medical case. For these two interviews, the researcher focused on questions that specifically ask for strengths and weaknesses. There were no follow-up interviews for this study. Data collection took place from mid-June to mid-July 2019.

\section{Data analysis}

This study used framework analysis with the aim to manage and identify themes. SU transcribed all recorded interviews and translated transcripts into English where needed. This process helped the research to be familiar with the content of each interview and to get a general overview of each participant's responses, while focusing on the relevance to the main objective of the study. Framework analysis was particularly chosen for this study because it helped the researchers to classify data in relation to the main imposed themes which are strengths and weaknesses of the TSAM-MNCH clinical mentoring model. This approach also enabled the research team to identify subthemes and to interpret data. The research team thoroughly reviewed and 
classified all ideas that emerged from the transcription process by focusing on the main objective as reflected in the research questions.

Each participant was assigned a code and then personal identifiers were deleted to ensure confidentiality. The first set of coding process was done manually by SU and there was no use of any computer software. SU read all transcripts and conducted the first set of coding. Other members of the research team further independently reviewed the initial set of coding and suggested some additions to enhance the readability of the results. After revisions, codes were assigned to the themes and subthemes which emerged from the transcripts. Great attention was paid on quotes and statements which responded to the research themes.

\section{Ethical consideration}

At the time of the study, the corresponding female researcher SU was a Master's student at the University of Edinburgh in the School of Social and Political Science. $\mathrm{SU}$ is a certified qualitative research by Market Research Society. An information sheet (online supplemental file 2) was provided to participants right before starting the interviews and then a written consent form to voluntarily participate in this study was signed by both the researcher (SU) and the participant. The consent forms were signed in the hospital offices, the same location where the interviews were conducted only between the participant and the researcher. Only the researcher had access to the interview recordings and consent forms, and there was no name attached to any recording or quotation to maintain the privacy and the confidentiality of the participants. TSAM-MNCH did not know the identity of mentors who participated in the study. The researcher has only shared a final report with TSAM-MNCH with no mentors' identities attached to it. The researcher's occupation, experience and study purpose were communicated to all participants. The study carried no risk to the participants.

\section{Patient and public involvement}

The mentorship programme is one of the key priorities of the health sector in Rwanda. ${ }^{21}$ Therefore, the development of the research question and outcome measures were done keeping this priority in mind. This study sample was only made of mentors providing mentorship programme and there was no interaction with patients. Therefore, it was not applicable to involve patients in the design of this study. This is the same for the involvement of the patients in the recruitment process. However, since mentors are involved in the management of the patients and in the provision of health services, the results of the study will be disseminated with different stakeholders including the hospitals and the Ministry of Health as well as the mentors themselves with a view to improve the clinical mentoring programme. This will be done through different meetings at different levels.

\begin{tabular}{|c|c|c|}
\hline Participants & Profession & Gender \\
\hline Interview 1 & Gynaecologist & Male \\
\hline Interview 2 & Anaesthetist & Male \\
\hline Interview 3 & Midwife & Female \\
\hline Interview 4 & Paediatrician & Female \\
\hline Interview 5 & Nurse & Female \\
\hline Interview 6 & Gynaecologist & Male \\
\hline Interview 7 & Midwife & Female \\
\hline Interview 8 & Paediatrician & Male \\
\hline Interview 9 & Nurse & Female \\
\hline Interview 10 & Anaesthetist & Female \\
\hline Interview 11 & Nurse & Male \\
\hline Interview 12 & Midwife & Female \\
\hline Interview 13 & Gynaecologist & Female \\
\hline Interview 14 & Paediatrician & Male \\
\hline
\end{tabular}

\section{RESULTS}

In this section, results are presented based on key themes identified vis-à-vis the mentors' perspectives of the TSAM-MNCH mentorship model. Two themes were developed and imposed as strengths and weaknesses of the programme. Two subthemes were classified under the theme of mentors' perceptions of the strengths of the scheme, and those are interprofessional collaboration, and training and facilitation. Also, two subthemes were identified under the theme of perspective of the weaknesses of the mentorship scheme, and those are the inconsistency of mentorship activities and lack of resources. These four subthemes emerged from the transcripts and were classified under each imposed theme according to the relevance with the research objective. Mentors' perspectives varied across different professions which means that there were no particular perspectives that emerged from one profession. Table 1 indicates details about the study participants.

\section{Perceived strengths of the TSAM-MNCH mentorship model}

This theme contains two categories that mentors perceived as the core strengths of the TSAM-MNCH mentorship model. The categories were developed based on what mentors viewed as factors that facilitate and ease the implementation of clinical mentorship in district hospitals. Those categories are interprofessional collaboration, and training and facilitation.

\section{Interprofessional collaboration}

Throughout all interviews, mentors demonstrated an appreciation and importance of collaboration among different medical professionals. The interprofessional collaboration was reported as an efficient strategy to provide quality care to mothers and children because it allows cross-consultation in the three inter-related departments that are important to the well-being of mothers and 
children, namely maternity, neonatal and paediatrics. Therefore, mentors appreciate working together while they are helping their mentees to acquire more skills and knowledge. A mentor stated:

If we delivered a premature baby in maternity, it is possible that it may end up in neonatology. We may monitor a mother who might end up having a Csection, we feel relieved if we are working closely with the neonatology and operating room teams. All these departments work together to improve the quality of care given to mothers and children, and to avoid deaths. (Midwife, interview 3)

In addition, mentors reported that this interdisciplinary approach increased their shared experience and learning opportunities where professionals learn from each other (gynaecologist, interview 1; midwife, interview 3 ; paediatrician, interview 8 and gynaecologist, interview 13). This is also important for mentees as they learn from that shared experience through case discussions, bedside teaching, simulation and collective feedback. There is a general accord among mentors that interprofessional collaboration increases confidence, competition and comfortability for both mentors and mentees. TSAMMNCH mentors believe that their collaborative behaviours are more likely to be mimicked by their mentees and their skills are transferred as well. They also stated that working together makes it easier to build a great teaching environment and to transfer skills by involving their mentees in clinical cases and activities. A mentor remarked:

I believe that as my mentee observe how I involved my colleagues from other departments in important decisions regarding the patients, he will learn from me and adopt the same strategy. (Paediatrician, interview 8)

\section{Training and facilitation}

Mentors applauded TSAM-MNCH Rwanda for facilitating mentoring activities and providing regular training. Mentoring activities take place in district hospitals, but all mentors regularly work at referral and university teaching hospitals. Mentors appreciated that TSAM-MNCH Rwanda provides accommodation, transport and financial payment during mentorship field visits (anaesthetist, interview 2; gynaecologist, interview 6; nurse, interview 11 and gynaecologist, interview 13). Mentors perceive such facilitation as a motivation to keep them engaged and as valuable consideration of their contribution to clinical teaching.

Most mentors can agree with me that financial motivation is very important. We get paid to do this job and our hotels and transport are also paid by TSAMMNCH Rwanda. (Gynaecologist, interview 13)

Additionally, mentors reported that TSAM-MNCH Rwanda regularly provides them with training on clinical mentorship, simulation, quality improvement, genderbased violence, and on updated medical skills and national protocol in $\mathrm{MNCH}$ (anaesthetist, interview 2; paediatrician, interview 4; nurse, interview 11 and paediatrician, interview 14). TSAM-MNCH mentors indicated that pieces of training are mainly based on emergency obstetrics and newborn care courses to increase their skills and knowledge. Mentors perceive refresher training as useful tools that enable them to better transfer skills to their mentees based on national updated protocol and standards. Mentorship training helped mentors to build a strong mentorship environment as well as a good teaching environment for their mentees. Mentors focused on communication skills and feedback strategies as important lessons learnt via TSAM-MNCH training. One mentor stated:

Refresher training that we receive every three months are essential to stay updated and to transfer skills to our mentees. What can we teach our mentees if we are not trained? I can also say that training helps us to build a better relationship with our mentees and the hospital administration. We were chosen due to our medical knowledge and experience, but TSAM$\mathrm{MNCH}$ trained us to become better teachers and role models. (Paediatrician, interview 14)

Mentors felt very confident and skilled to conduct mentorship activities. When asked about their perceived confidence and ability to transfer skills, mentors rated themselves out 10 and the lowest point was 8/10 and the highest was $9.5 / 10$. They believe that they got the ability to become mentors through the training. Mentors strongly believe that TSAM-MNCH is contributing a lot to the CPD in the medical field of Rwanda.

However, mentors are concerned that the training programmes are more centred on mentors than on mentees. Additional benefits are only given to mentors in terms of financial means and training which they consider as a motivation to keep them fully engaged in mentoring activities. Therefore, mentors believe that mentees are less motivated and that more rewards are needed to keep mentees determined and committed (gynaecologist, interview 1; midwife, interview 7 and nurse, interview 11).

Mentees rarely receive any kind of training. They are not paid for the involvement in mentoring while mentors are paid. If you look closely, mentees contribute extra time and commitment to be part of the programme, therefore, not receiving any motivation such as a small payment can negatively impact their determination and engagement to the programme. (Midwife, interview 7)

\section{Perceived weaknesses of the TSAM-MNCH mentorship model}

The following theme describes two categories that the TSAM-MNCH mentors perceived as the weaknesses of the mentorship model. The categories were developed based on what mentors perceived as the barriers to better 
implementation of clinical mentorship in district hospitals. Those categories are inconsistency of mentorship activities and the lack of resources.

\section{Inconsistency of mentorship activities}

TSAM-MNCH mentors reported the lack of consistency in mentorship field visits (anaesthetist, interview 2; midwife, interview 7 and nurse, interview 9). It was stated that since the beginning of the project, the frequency and the regularity of mentoring visits have reduced over time. The mentorship visits should occur once in 2 months, but mentors reported that they can go over 3 months without any mentorship field visits. Such changes are not appreciated by mentors because they affect the regularity of the mentorship process, and hence complicate the teaching process and the transfer of skills. Though mentors can fulfil their mentorship roles anytime through regular communication with their mentees via phone or email, mentors believe that ongoing distant communication cannot cover the gap created by lack of onsite teaching (midwife, interview 3 and midwife, interview 12). The following quote demonstrates this idea.

The programme does not run the way it is supposed to run, we started by one visit per two months, but now I don't even know how many months have passed since the last visit. I feel like we spend a lot of time teaching a few skills because mentees are more likely to forget what we covered last time. Plus, we do not have mentoring schedules. (Midwife, interview 12)

As mentioned by mentors, inconsistency is also observed through the frequent mentees' turnover where mentees are shifted from hospital to hospital, which marks the end of a mentorship relationship (gynaecologist, interview 1; midwife, interview 3; nurse, interview 5 and midwife, interview 12). Mentors are then supposed to pick other mentees in the middle of the mentorship activities. Such changes interrupt mentorship activities as it becomes hard to catch up with a new mentee. A mentor stated:

The hospital administration changes mentees' position a lot, they either switch hospitals or departments due to the shortage of staff and we are not informed when this happens. Some mentees start the programme, but they never finish it and we must pick another mentee to replace the one who left, and this means starting all over. (Nurse, interview 5)

Mentors added that mentorship visits often conflict with mentees' annual leave or night shifts, which limit the mentees' ability to attend mentorship sessions (anaesthetist, interview 10 and midwife, interview 12). Mentors conveyed that mentees use their discretion to decide if they would attend mentorship visits when they are on annual leave or working night shifts. Lack of proper learning and feedback is one of the effects of these irregularities as reported by mentors. Busy work schedules due to shortage of healthcare workforce can also deprive mentees from fully attending mentorship sessions (paediatrician, interview 4 and midwife, interview 12). Mentors think this workforce shortage is not conducive for teaching purposes because they are supposed to rush through mentorship activities so that mentees can resume their normal duties.

There are places where one nurse is in charge of almost everything, to assist in surgery, to sterilize materials and to monitor the patient post-operation. This leads to a lack of proper documentation and sometimes, hospitals cleaners are the ones to transport patients and cleaners should not touch patients, now tell me, how can you teach in such an environment. Over 3 days, you can see the mentee once or twice for only a few hours. You take another person when your mentee is not around. It is hard to monitor the performance and mentor someone in such conditions. (Paediatrician, interview 4)

Mentors also mentioned that the irregularity of mentorship activities can affect the relationship between the mentor and the mentee for they are not working closely on a regular basis. A few mentors mentioned some mentors are not very committed to the programme because they rarely show up during mentorship visits (anaesthetist, interview 10 and gynaecologist, interview 13). They think that mentors' unavailability can also disrupt the consistency of mentorship visits as well as the relationship with their mentees.

Some of my fellow mentors also are part of the question, they occasionally miss field mentorship visits and in my experience I can say that this absence limit the transfer of skills to the mentees. (Anaesthetist, interview 10)

\section{Resource unavailability}

Lack of materials is the main challenge for most hospitals that was reported by all mentors. Due to lack of basic medical materials in many hospitals, it became hard for mentors to enhance best practice and to ensure that their mentees are following national protocol. In addition, mentors view poor infrastructures in some hospitals as a barrier to create a proper teaching environment. Hospital settings in a few hospitals are deemed unconducive for quality improvement and they limit the ability of mentors to transfer medical skills. The following quote shows this issue.

At this hospital, there are no CPAP therefore; I taught my mentee how to use artificial CPAP. Another issue that is common here is that babies sometimes have to share oxygen cylinders because the hospital does not have enough. Oh well, there are a lot of issues with materials; a mentor from another hospital told me that they only have one labour monitor in their maternity services, but there is often a big number of mothers in labour at the same time. (Nurse, interview 11) 
Mentors acknowledge that some issues are beyond the hospital management due to limited resources and insufficient budgets and they sometimes use TSAM-MNCH advocacy to increase the storage of more essential materials. However, some mentors added that though there is a lack of materials and equipment, the lack of skills among healthcare providers is also concerning and some skills do not need the use of equipment (anaesthetist, interview 2 and gynaecologist, interview 13).

Believe it or not, the issue of limited resources is often beyond the hospital management. But the use of skills does not only really depend on materials and equipment because they always have the basics, but sometimes they either neglect to use them or they overlook some few steps that are critical for patient care. They may be focusing more on equipment, but I can say that most of the things like $70 \%$ would not require the use of extra equipment. (Anaesthetist, interview 2)

\section{DISCUSSION}

This study explored mentors' perspectives on the strengths and weaknesses of the TSAM-MNCH clinical mentorship for $\mathrm{MNCH}$ programme in Rwandan district hospitals. Mentors commended the mentoring structures of interprofessional collaboration and training and facilitation, which play a significant role in the successful implementation of the mentorship model. Inconsistency of mentoring activities and lack of resources emerged as major weaknesses of the clinical mentorship programme which could hinder the effectiveness of the mentoring scheme.

\section{Interprofessional collaboration}

A cross-consultation among professionals enables mentors to assess risks, increase performance and improve quality of care given to mothers and children. These outcomes of collaboration are consistent with what Meads and Ashcroft ${ }^{22}$ described as the three pillars of interprofessional accountability and collaboration. Collaborative effort of all concerned parties is central as patients do not mostly belong to one professional category, but to all who provide care and take measures to avoid preventable errors. ${ }^{21}$ Mentors perceive that shared accountability between different professionals stands as the strongest cornerstone of the TSAM-MNCH mentorship model. It is believed that collaboration can improve performance through dependency and cross-consultation between departments; however, the evaluation of performance was beyond the scope of this study. ${ }^{22}$

\section{Training and facilitation}

Regular training serves as a CPD opportunity for mentors that enhance their knowledge and skills on mentorship, gender-based violence, quality improvement, maternal mental health and national protocols. In addition, training on mentorship enables mentors to build a positive mentoring environment which mentors believe to also be beneficial for mentees. The confidence level is also believed to be boosted by training that mentors receive on a regular basis. This finding is similar to what Tuyisenge $e t a l^{23}$ highlighted that CPD training serves as useful tools to train the trainers in different mentorship projects in Rwanda. Literature demonstrates that such refresher training ensures that practitioners are trained on updated protocol and national guidelines which can contribute to the improvement of MCH especially in rural areas, similar to those in which TSAM-MNCH mentors are conducting their activities. ${ }^{11} 1823$

Another unexpected finding in this study, compared with the existing literature, is the mentors' perceptions of limited motivation geared toward mentees. Our findings are consistent with Reilly's study ${ }^{24}$ which found that mentees need to be actively and passionately engaged and that learner's motivation is a precondition to ensure the efficient transfer of skills. ${ }^{24}$ It is, however, important to keep in mind that the idea of the mentorship was that mentors would be training the mentees. However, CPD credits were received by mentees to increase their motivation and to keep their professional licences. A study that focuses on mentees' perspectives of the TSAM-MNCH mentorship programme could shed light on motivation of mentees.

\section{Inconsistency of mentorship activities}

The lack of consistency of mentorship activities and schedules is one of concerns of TSAM-MNCH mentors. This is related to the shortage and the frequent turnover of healthcare workers in district hospitals of Rwanda. This sometimes may have a negative effect on the relationship between a mentor and a mentee. This issue is also consistent in other mentorship programmes in Rwanda especially with the frequent shift of their mentees which disrupts the stability of mentorship activities. ${ }^{25}{ }^{26}$ TSAMMNCH Rwanda acknowledges such inconsistency, but some of it was beyond its control. Some visits were postponed due to conflicting agenda.

The literature on mentor-mentee relationship demonstrated that the mentorship relationship can be disrupted by inadequate systems which fail to ensure the establishment of a strong relationship between mentors and mentees and the continuity of professional collaboration which creates an opportunity for mutual understanding and communication. ${ }^{22}$ Therefore, it can be inferred that the disruption of clinical activities and the staff turnover are factors that can impede a better relationship between mentor and mentee.

\section{Resources unavailability}

Lack of resources to implement all recommendations of mentors is another perceived weakness that hinders the activities of TSAM-MNCH mentorship programme. Literature reveals that this is a common challenge throughout different hospitals in low-resource countries. ${ }^{1627}$ Therefore, 
it is no surprise that TSAM-MNCH mentors perceive the lack of resources as a weakness similar to other mentorship projects. ${ }^{25}{ }^{27}$ This lack of resources may also affect the scalability and or sustainability of the programme. This study results also show that mentors appreciate TSAM-MNCH advocacy to increase storage of essential materials in their affiliated hospitals, which have benefited and facilitated mentorship activities, but the issue persists.

\section{Study limitations}

This study has some limitations. Although mentors are affiliated to their professional associations and to their working institutions, they are also TSAM-MNCH's active mentors and they were recruited using the contact information provided by the programme. Therefore, regardless of their anonymous identities, participants might have some reservations and/or bias toward TSAM-MNCH that can be reflected in perspectives that were gathered during the interviews and hence affect the reliability of mentors' accounts. This is important because this study is heavily based on the perspectives of the mentors, which are merely the points of views of participants which might influence their behaviours and their attitudes toward the scheme. ${ }^{28-30}$

The study recognises that the inclusion of mentees and other healthcare providers, not affiliated with TSAM$\mathrm{MNCH}$, working within districts hospitals where TSAM$\mathrm{MNCH}$ is based would have provided a richer and diverse set of perspectives about the programme. Future consideration of these limitations would be beneficial for a deeper understanding of the perceptions of the project's impact since the scope and the time frame of this study did not allow that possibility.

Furthermore, due to limited availability of mentors and the urgency of their professions, two interviews only lasted for $35 \mathrm{~min}$ and the researcher had to prioritise some interview questions over others. This constraint could lead to superficial responses from mentors which can hence limit the researcher's need to get a deeper understanding of perspectives. However, this limitation is demonstrated in only two interviews and the researcher tried to cover the gap by getting detailed responses from other 12 interviews and by reaching saturation with the themes.

Finally, it might be hard for an interviewer to truly know someone's perception; therefore, further research is needed that evaluates measurable indicators of the scheme's impact to complement this research. The study findings are very important to TSAM-MNCH Rwanda as they provide insights on the perspectives of mentors which can guide future research and inform the strengthening of this mentorship programme. However, the study makes a significant contribution to the limited literature on the perspectives of the impact of clinical mentorship for healthcare providers in Rwanda.

\section{CONCLUSION}

Interprofessional collaboration and CPD training are the core strengths of the TSAM-MNCH clinical mentorship programme. On the other hand, the lack of resources and the inconsistency of mentorship activities both in terms of mentorship visits due to conflicting agenda and frequent turnover of mentees in their hospital are perceived weaknesses that limit the proper implementation of the TSAM-MNCH mentorship programme. Regardless of the reported perceived weaknesses, TSAM$\mathrm{MNCH}$ mentors demonstrated a deep engagement in clinical teaching through mentoring which is a promising sign for improving the quality of care for mothers and children. The continuous training of healthcare workers is reported to be an effective way of improving skills and knowledge, bridging the gap between didactic knowledge and practice and thus enhance performance. However, the mere application of mentorship techniques and training does not ensure that practice habits are changed, and that quality care has improved. Therefore, a study to assess providers' performance and change in practice is deemed necessary.

\section{Author affiliations}

${ }^{1}$ School of Social and Political Science, The University of Edinburgh, Edinburgh, UK ${ }^{2}$ Economic Community of Central African States (ECCAS), Libreville, Gabon

${ }^{3}$ Midwifery Department, College of Medicine and Health Sciences- University of Rwanda, Kigali, Rwanda

${ }^{4}$ Department of Global Health and Population, Harvard TH Chan School of Public Health, Boston, Massachusetts, USA

${ }^{5}$ Perinatal Medicine, Western University Schulich School of Medicine and Dentistry, London, Ontario, Canada

${ }^{6}$ University of Rwanda College of Medicine and Health Sciences, Kigali, Rwanda ${ }^{7}$ Western University Schulich School of Medicine and Dentistry, London, Ontario, Canada

Acknowledgements The authors would like to thank all mentors who participated in this research. Since the corresponding author received funding from the University of Edinburgh, School of Social and Political Science, the researchers' team would like to extend their gratitude to the institution.

Contributors SU designed the research, collected and analysed the data, and drafted the manuscript. AN provided supervision for the subject selection and data collection, and critical revisions of the manuscript. $\mathrm{OB}, \mathrm{CH}, \mathrm{CKe}, \mathrm{DA}$ and $\mathrm{CKa}$ contributed to the analysis and interpretation of the results, and reviewed the paper. DC supervised the design and implementation of the research and critical revisions of the manuscript. All authors have read and approved the final version of the manuscript for submission.

Funding This research received financial support from the University of Edinburgh, School of Social and Political Science. The study was conducted as part of the Global Health Policy Programme. It was not a grant.

Competing interests None declared.

Patient consent for publication Not required.

Ethics approval Ethical clearance was obtained from the CMHS-IRB of the University of Rwanda (Approval Notice: No 346/CMHS IRB/2019) and the School of Social and Political Science at the University of Edinburgh (Approval ID: 'Workbased placement' (ID: 262188)). The researchers were granted permission by the TSAM-MNCH Rwanda administration to conduct this study.

Provenance and peer review Not commissioned; externally peer reviewed.

Data availability statement Data are available upon reasonable request. The datasets used in this study may be available from the corresponding author upon a reasonable request (angesandra18@gmail.com).

Supplemental material This content has been supplied by the author(s). It has not been vetted by BMJ Publishing Group Limited (BMJ) and may not have been peer-reviewed. Any opinions or recommendations discussed are solely those of the author(s) and are not endorsed by BMJ. BMJ disclaims all liability and responsibility arising from any reliance placed on the content. Where the content 
includes any translated material, BMJ does not warrant the accuracy and reliability of the translations (including but not limited to local regulations, clinical guidelines, terminology, drug names and drug dosages), and is not responsible for any error and/or omissions arising from translation and adaptation or otherwise.

Open access This is an open access article distributed in accordance with the Creative Commons Attribution Non Commercial (CC BY-NC 4.0) license, which permits others to distribute, remix, adapt, build upon this work non-commercially, and license their derivative works on different terms, provided the original work is properly cited, appropriate credit is given, any changes made indicated, and the use is non-commercial. See: http://creativecommons.org/licenses/by-nc/4.0/.

\section{ORCID iD}

Anaclet Ngabonzima http://orcid.org/0000-0001-8712-5348

\section{REFERENCES}

1 World Health Organization. Maternal and newborn data, 2019. Available: https://www.who.int/data/maternal-newborn-childadolescent/maternal-and-newborn-data [Accessed 25 Jul 2019].

2 Ralston ME, Day LT, Slusher TM, et al. Global paediatric advanced life support: improving child survival in limited-resource settings. Lancet 2013;381:256-65.

3 Buchanan C, Okoth P, Yigzaw A. The pregnant patient. in: principles of medicine in Africa. Cambridge: Cambridge University Press, 2013.

4 World Health Organization. World health statistics 2015. Available: https://www.who.int/docs/default-source/gho-documents/worldhealth-statistic-reports/world-health-statistics-2015.pdf [Accessed 21 Aug 2020].

5 Word Health Organization, UNICEF, UNFPA, World Bank Group. Trends in maternal mortality 2000 to 2017. Available: https://apps. who.int/iris/bitstream/handle/10665/327596/WHO-RHR-19.23-eng. pdf?sequence $=13$ \&isAllowed=y [Accessed 30 Aug 2020].

6 National Institute of Statistics of Rwanda (NISR). Rwanda demographic health survey 2014-2015. Kigali. Available: https:// dhsprogram.com/pubs/pdf/FR316/FR316.pdf

7 McNamara MS, Fealy GM, Casey M, et al. Mentoring, coaching and action learning: interventions in a national clinical leadership development programme. J Clin Nurs 2014;23:2533-41.

8 Kassie GM, Belay T, Sharma A, et al. Promoting local ownership: lessons learned from process of transitioning clinical mentoring of HIV care and treatment in Ethiopia. Front Public Health 2018;6:14.

9 World Health Organization. WHO recommendations for clinical mentoring to support scale-up of HIV care, antiretroviral therapy and prevention in resource-constrained settings, 2005. Available: https:// www.who.int/hiv/pub/guidelines/clinicalmentoring.pdf [Accessed 2 Sep 2019].

10 Okereke E, Tukur J, Aminu A, et al. An innovation for improving maternal, newborn and child health $(\mathrm{MNCH})$ service delivery in Jigawa state, Northern Nigeria: a qualitative study of stakeholders' perceptions about clinical mentoring. BMC Health Serv Res 2015;15:64.

11 Workneh G, Scherzer L, Kirk B, et al. Evaluation of the effectiveness of an outreach clinical mentoring programme in support of paediatric HIV care scale-up in Botswana. AIDS Care 2013;25:11-19.
12 Manzi A, Hirschhorn LR, Sherr K, et al. Mentorship and coaching to support strengthening healthcare systems: lessons learned across the five population health implementation and training partnership projects in sub-Saharan Africa. BMC Health Serv Res 2017;17:831.

13 Shikuku DN, Mukosa R, Peru T, et al. Reducing intrapartum fetal deaths through low-dose high frequency clinical mentorship in a rural hospital in Western Kenya: a quasi-experimental study. BMC Pregnancy Childbirth 2019;19:518.

14 Manzi A, Magge H, Hedt-Gauthier BL, et al. Clinical mentorship to improve pediatric quality of care at the health centers in rural Rwanda: a qualitative study of perceptions and acceptability of health care workers. BMC Health Serv Res 2014;14:275.

15 Kanchanachitra C, Lindelow M, Johnston T, et al. Human resources for health in Southeast Asia: shortages, distributional challenges, and international trade in health services. Lancet 2011;377:769-81.

16 Hategeka C, Shoveller J, Tuyisenge L, et al. Pediatric emergency care capacity in a low-resource setting: an assessment of district hospitals in Rwanda. PLoS One 2017;12:e0173233.

17 Ngabonzima A, Kenyon C, Hategeka C, et al. Developing and implementing a novel mentorship model $\left(4^{+1}\right)$ for maternal, newborn and child health in Rwanda. BMC Health Serv Res 2020;20:924.

18 Binagwaho A. Maternal and child health: clinical mentoring guidelines. Kigali: The Ministry of Health, 2016.

19 Alliance for Health Policy and Systems Research, World Health Organisation. Primary health care systems (Primasys): case study from Rwanda. Available: https://www.who.int/alliance-hpsr/projects/ AHPSR-PRIMASYS-Rwanda-Abridged.pdf?ua $=1$

20 National Institute of Statistics of Rwanda (NISR), Ministry of Health Rwanda, Macro International. Rwanda service provision assessment survey, 2007. Available: https://dhsprogram.com/pubs/pdf/SPA15/ SPA15.pdf

21 Liamputtong P. Qualitative inquiry. In: Handbook of research methods in health social sciences. Springer, 2019.

22 Meads G, Ashcroft J. The case of interprofessional collaboration: in health and social care. Oxford: Blackwell Publishing, 2005.

23 Tuyisenge G, Hategeka C, Luginaah I, et al. Continuing professional development in maternal health care: barriers to applying new knowledge and skills in the hospitals of Rwanda. Matern Child Health J 2018;22:1200-7.

24 Reilly BM. Inconvenient truths about effective clinical teaching. Lancet 2007:370:705-11.

25 Magge H, Chilengi R, Jackson EF, et al. Tackling the hard problems: implementation experience and lessons learned in newborn health from the African health Initiative. BMC Health Serv Res 2017;17:829.

26 Anatole M, Magge H, Redditt V, et al. Nurse mentorship to improve the quality of health care delivery in rural Rwanda. Nurs Outlook 2013;61:137-44.

27 Nolan T, Angos P, Cunha AJ, et al. Quality of hospital care for seriously ill children in less-developed countries. Lancet 2001;357:106-10.

28 Magge $\mathrm{H}$, Anatole M, Cyamatare FR, et al. Mentoring and quality improvement strengthen integrated management of childhood illness implementation in rural Rwanda. Arch Dis Child 2015;100:565-70.

29 Lagerspetz O. Studying perception. Philosophy 2008;83:193-211.

30 Livingston P, Evans F, Nsereko E, et al. Safer obstetric anesthesia through education and mentorship: a model for knowledge translation in Rwanda. Can J Anesth/J Can Anesth 2014;61:1028-39. 